\title{
Injuries and training variables in Filipino judo athletes
}

\author{
Reylin Maciejewski ${ }^{1}$, Hercules Callanta $^{2}$ \\ ${ }^{1}$ Department of Sport Marketing, College of Physical Education, Keimyung University, Daegu, South Korea; ${ }^{2}$ Department \\ of Sport Science, College of Human Kinetics, University of the Philippines, Diliman, Philippines
}

\section{Summary}

Study aim: The aim of this study was twofold: first, to compare the incidence of injuries between male and female athletes in the junior and youth divisions during competition, as well as to identify body parts commonly injured and the types of injury frequently incurred; second, to assess overall incidence of injuries in relation to the frequency and duration of training as well as supplemental training.

Material and methods: Subjects were Filipino judokas $(\mathrm{n}=192)$ competing in 4 major divisions at a national competition in Manila in 2009. Injury rates are expressed per 1,000 athlete-exposures, and the confidence intervals around the rates were computed.

Results: There was no difference in injury rate between boys (84.03/1,000 athlete-exposures (A-E), 95\% CI: 47.20-120.86) and girls (37.04/1,000 A-E, 95\% CI: -14.29-88.37). Although the boys were at a higher risk than the girls, the difference was not significant $(\mathrm{OR}=3.13,95 \% \mathrm{CI}$ : $0.62-15.76)$. The junior women were at a higher risk than the girls $(\mathrm{OR}=6.30,95 \% \mathrm{CI}$ : 1.26-31.66). Neither training frequencies of $\leq 2,3$, and $\geq 4$ sessions per week nor training durations of $\leq 2$ and $>2$ hours were significant predictors of injury. Supplemental training was not found to be related to the occurrence of injuries.

Conclusion: Judo is a relatively safe physical activity for young adults and children. Training variables, such as frequency and duration, and supplemental training do not influence the occurence of injury.

\section{Key Words: Judo - Injuries - Epidemiology - Training - Athletes}

\section{Introduction}

Since its beginnings in Japan, judo has become one of the most popular Olympic sports in the world [17]. Out of the 204 member nations of the International Olympic Committee [25], 201 are members of the International Judo Federation [10]. Judo was first included at the 1964 Olympic Games in Tokyo, was then absent from Mexico City in 1968, and has been a permanent part of the programme since 1972 in Munich [13]. Only the men's categories were included until the Barcelona games in 1992 when the women's division was finally recognized as an official part of the event.

Judo is fundamentally a highly technical sport and is based on the major principle of "maximum efficiency with minimum effort" as originally espoused by Jigoro Kano, the founder of judo [15]. In an effort to achieve this ideal, the principles of leverage and balance are essential in the successful execution of judo throws. Aside from throwing, there are also grappling techniques (ne-waza) that are performed with the aim of subduing an opponent by pinning them down to the ground (osaekomi-waza) or via submission through a choke hold (shime-waza) or arm joint lock (kansetsu-waza). As in any other contact sport, the occurrence of injuries in judo is of concern, and the risks involved may be higher than they are for team sports, especially since judo has become popular among children [18].

Most investigations of judo injuries have initially focused on case studies [35] and have used retrospective designs based on databases [16]. The case series in judo mostly involve rare occurrences in the sport, such as avulsion of the hamstring tendons [19], distal radio-ulnar dislocation [35], or a combined-force-injury of the elbow joint [22]. A survey of the current publications revealed a smattering of case reports [36], as well as prospective studies [12], and a few retrospective studies [5]. The latter investigated the occurrence of injuries in relation to the types of techniques used, while Koshida et al. [17] implicated the grip style of competitors as the culprit for many anterior cruciate ligament (ACL) injuries. Prospective 
designs address the limitations of retrospective designs and have been used in a number of investigations. For instance, Pieter and De Crée [30] reported that injury rates were higher in female athletes (girls $=98.6 / 1,000$ athleteexposures (A-E); junior girls $=150.0 / 1,000 \mathrm{~A}-\mathrm{E}$; women $=$ $125.0 / 1,000 \mathrm{~A}-\mathrm{E}$ ) than in male athletes (boys $=79.7 / 1,000$ A-E; junior boys $=62.5 / 1,000$ A-E; men $=51.3 / 1,000$ A-E) in all age divisions, according to a survey conducted among young and adult athletes at an international tournament in the UK. Athlete exposure (A-E) is defined as "one athlete participating in one practice/game in which there is a possibility of sustaining an injury" [7].

Prospective studies that follow a similar methodology show that the upper limbs, as well as the head and neck, are the most susceptible to injury in junior competitors [11]. However, compared with senior athletes, the upper extremities were still found to be at risk, but knees were also found to be prone to injury [32]. When it comes to injury types, the majority of these studies identified contusions and abrasions as the most frequent injuries [8], across all age divisions.

In comparison with other sports, judo has a low recorded incidence of injuries, although when they do occur, they are usually severe, requiring days off from practice or competition [39]. In almost every tournament covered in previous studies, there was at least one major and severe injury, such as a fracture, dislocation or concussion [e.g., 32]. There were, however, significantly fewer judo injuries $(4.8 \%, 95 \%$ CI: $2.9-6.9)$ than karate injuries (79.5\%, 95\% CI: 78.6-80.4) reported out of all the sports sampled in a paediatric study on martial arts [41].

Not many studies on judo injuries in children can be found in the literature. James and Pieter [11], for instance, found that junior male (39.76/1,000 A-E) and junior female judokas (52.08/1,000 A-E) incurred lower rates compared to other combat sports. Pieter and De Crée [30], on the other hand, reported higher rates with girls incurring more injuries $(98.6 / 1,000 \mathrm{~A}-\mathrm{E})$ compared to boys $(79.7 / 1,000$ A-E) as well as junior women (150.0/1,000 A-E) compared to junior men (62.5/1,000 A-E).

So far, only one study has investigated the relationship between injury rates and training variables, such as volume and intensity. Although Bacanac et al. [3] found that adults trained twice as much as their younger counterparts, the percentage of injuries reported were not twice as high, which led the authors to conclude that there might be other factors involved in the training process that affect an athlete's susceptibility to injury, such as the programme being used, the psychological make-up of the athletes, and the use of improper equipment.

No previous prospective studies on the incidence of injuries involving young Filipino judoka (judo practitioners) are currently available. As documented, most investigations have focused on the incidence or rate of injuries in relation to age, sex or skill level. The relationship between the incidence of injuries and training variables, such as the frequency and duration of training has not been investigated except by Bacanac et al. [3]. Furthermore, no attempt has yet been made to identify a possible relationship between injuries and supplemental training. The aim of this study, therefore, was twofold: first, to compare the incidence of judo injuries between male and female athletes in the junior and youth divisions in competitions; and second, to assess injury rates in relation to the frequency and duration of training and to examine the role of supplemental training.

\section{Material and methods}

Filipino judo athletes $(\mathrm{n}=192)$ who competed in the 2009 Philippine National Juniors Judo Championships in Manila were recruited to participate in this study. There were 4 major divisions: junior men $(n=76,17.67 \pm 1.08$ years) and junior women $(\mathrm{n}=52,17.64 \pm 1.13$ years $)$, as well as boys $(\mathrm{n}=52,11.97 \pm 2.40$ years $)$ and girls $(\mathrm{n}=12$, $11.88 \pm 2.60$ years) divisions. All subjects completed an informed consent form that was signed by the parents/guardians of the participants. This project was approved by the Research Committee at the second author's institution.

A data collection form was completed for every injury for which treatment was sought by the athletes, referees or coaches from the medical staff at the competition site. An injury was defined as any circumstance for which assistance was sought from the medical personnel during the competition [31]. This definition considers all injuries occurring on-site, whether they were acute, present prior to the competition or recurred during the same competition. All diagnoses were made by the tournament physician. A modified injury form [12] was completed in collaboration with the attending tournament physician. Injuries are expressed per A-E.

To obtain total A-E and A-E's in the different divisions, the following basic formula was used in this study: Incidence Rate $=$ (\# new events during specified time period $\times \mathrm{k}) \div \#$ in the population at risk, where new events refer to injuries, $\mathrm{k}$ is a constant multiple of 10 , and the population at risk refers to the number of people exposed to the possibility of getting injured or A-E. A more detailed explanation of calculating case rates using this formula is explained elsewhere by Zemper and Randall [43]. To get the A-Es in this study, the number of matches gathered from the records were multiplied by 2 since there were two judokas in every match who were exposed to getting injured [8].

Injury frequency and injury rate for each body region and body parts were identified. In addition to injury rates per 1,000 A-E, confidence intervals (CIs) around the rates 
were also computed. Odds ratios were calculated to compare the injury rates between gender and between division. A logistic multiple regression was used to assess the extent to which injuries were related to training variables. A binary logistic regression with supplemental training as the categorical predictor variable was employed to assess the relationship between supplemental training and the occurrence of injuries. Due to the small sample and cell sizes, all age groups were combined for the regression analyses.

\section{Results}

There was no significant difference in injury rates between the sexes in both age categories (Table 1). Boys incurred a higher injury rate than girls $(\mathrm{OR}=3.13,95 \% \mathrm{CI}$ : 0.62-15.76), women had a higher rate also than men $(\mathrm{OR}=1.20,95 \% \mathrm{CI}: 0.59-2.43)$, and men compared to boys, $(\mathrm{OR}=1.69,95 \% \mathrm{CI}: 0.82-3.46)$, but these relationships

Table 1. Injury rates $(95 \% \mathrm{CI})$ in junior men and women, boys and girls

\begin{tabular}{lccccc}
\hline & Total & Junior Men & Junior Women & Boys & Girls \\
\hline Number of athletes & 192 & 76 & 52 & 52 & 12 \\
Number of injuries & 90 & 39 & 29 & 20 & 2 \\
Number of A-E & 916 & 366 & 258 & 238 & 54 \\
IR per 1,000 A-E & $98.25(77.95-118.55)$ & $106.56(73.11-140.00)$ & $112.40(71.49-153.31)$ & $84.03(47.20-120.86)$ & $37.03(-14.29-88.37)$ \\
\hline
\end{tabular}

CI - confidence interval; A-E - athlete exposure; IR - injury rate.

Table 2. Injury rates $(95 \% \mathrm{CI})$ per body region/part in junior men and women and in boys and girls

\begin{tabular}{|c|c|c|c|c|c|c|c|c|}
\hline & & Junior Men & & Junior Women & & Boys & & Girls \\
\hline Region/Body part & $\#$ & Rate $(95 \% \mathrm{CI})$ & \# & Rate $(95 \% \mathrm{CI})$ & $\#$ & Rate $(95 \% \mathrm{CI})$ & $\#$ & Rate $(95 \% \mathrm{CI})$ \\
\hline HEAD \& NECK & 13 & $35.52(16.21-54.83)$ & 13 & $50.39(23.00-77.78)$ & 7 & $29.41(7.62-51.20)$ & 0 & 0 \\
\hline Head & 1 & $2.73(-2.62-8.09)$ & 1 & $3.88(-3.72-11.47)$ & 4 & $16.81(0.34-33.28)$ & 0 & 0 \\
\hline Neck & 1 & $2.73(-2.62-8.09)$ & 3 & $11.63(-1.53-24.79)$ & 0 & 0 & 0 & 0 \\
\hline Nose & 6 & $16.39(3.28-29.51)$ & 0 & 0 & 2 & $8.40(-3.24-20.05)$ & 0 & 0 \\
\hline Face & 3 & $8.20(-1.08-17.47)$ & 4 & $15.50(0.31-30.70)$ & 1 & $4.20(-4.03-12.44)$ & 0 & 0 \\
\hline Jaw & 0 & 0 & 1 & $3.88(-3.72-11.47)$ & 0 & 0 & 0 & 0 \\
\hline Lip & 2 & $5.46(-2.11-13.04)$ & 2 & $7.75(-2.99-18.50)$ & 0 & 0 & 0 & 0 \\
\hline Tongue & 0 & 0 & 2 & $7.75(-2.99-18.50)$ & 0 & 0 & 0 & 0 \\
\hline UPPER BODY & 20 & $54.64(30.70-78.59)$ & 11 & $42.64(17.44-67.83)$ & 8 & $33.61(10.32-56.91)$ & 1 & $18.52(-17.78-54.81)$ \\
\hline Hand & 5 & $13.66(1.69-25.64)$ & 5 & $19.38(2.39-36.37)$ & 3 & $12.61(-1.66-26.87)$ & 0 & 0 \\
\hline Forearm & 4 & $10.93(0.22-21.64)$ & 2 & $7.75(-2.99-18.50)$ & 0 & 0 & 0 & 0 \\
\hline Finger & 5 & $13.66(1.69-25.64)$ & 1 & $3.88(-3.72-11.47)$ & 1 & $4.20(-4.03-12.44)$ & 0 & 0 \\
\hline Wrist & 1 & $2.73(-2.62-8.09)$ & 0 & 0 & 0 & 0 & 0 & 0 \\
\hline Upper arm & 2 & $5.46(-2.11-13.04)$ & 0 & 0 & 1 & $4.20(-4.03-12.44)$ & 0 & 0 \\
\hline Shoulder & 1 & $2.73(-2.62-8.09)$ & 3 & $11.63(-1.53-24.79)$ & 2 & $8.40(-3.24-20.05)$ & 0 & 0 \\
\hline Elbow & 2 & $5.46(-2.11-13.04)$ & 0 & 0 & 1 & $4.20(-4.03-12.44)$ & 1 & $18.52(-17.78-54.81)$ \\
\hline LOWER BODY & 6 & $16.39(3.28-29.51)$ & 5 & $19.38(2.39-36.37)$ & 5 & $21.01(2.60-39.42)$ & 1 & $18.52(-17.78-54.81)$ \\
\hline Knee & 2 & $5.46(-2.11-13.04)$ & 1 & $3.88(-3.72-11.47)$ & 1 & $4.20(-4.03-12.44)$ & 0 & 0 \\
\hline Toe & 1 & $2.73(-2.62-8.09)$ & 0 & 0 & 3 & $12.61(-1.66-26.87)$ & 1 & $18.52(-17.78-54.81)$ \\
\hline Ankle & 1 & $2.73(-2.62-8.09)$ & 1 & $3.88(-3.72-11.47)$ & 0 & 0 & 0 & 0 \\
\hline Foot & 1 & $2.73(-2.62-8.09)$ & 3 & $11.63(-1.53-24.79)$ & 0 & 0 & 0 & 0 \\
\hline Thigh & 1 & $2.73(-2.62-8.09)$ & 0 & 0 & 1 & $4.20(-4.03-12.44)$ & 0 & 0 \\
\hline
\end{tabular}

$\mathrm{CI}$ - confidence interval. 
Table 3. Distribution of injuries by injury type per 1,000 A-E in junior men and women, boys and girls

\begin{tabular}{|c|c|c|c|c|c|c|c|c|}
\hline & & Junior Men & & Junior Women & & Boys & & Girls \\
\hline Injury type & $\#$ & Rate $(95 \%$ CI) & $\#$ & Rate $(95 \%$ CI) & \# & Rate $(95 \%$ CI) & $\#$ & Rate $(95 \%$ CI $)$ \\
\hline Abrasion & 12 & $32.79(14.24-51.34)$ & 10 & $38.76(14.74-62.78)$ & 6 & $25.21(5.04-45.38)$ & 1 & $18.52(-17.78-54.81)$ \\
\hline Contusion & 2 & $5.46(-2.11-13.04)$ & 4 & $15.50(0.31-30.70)$ & 7 & $29.41(7.62-51.20)$ & 1 & $18.52(-17.78-54.81)$ \\
\hline Sprain & 5 & $13.66(1.69-25.64)$ & 3 & $11.63(-1.53-24.79)$ & 3 & $12.61(-1.65-26.87)$ & 0 & 0 \\
\hline Strain & 1 & $2.73(-2.62-8.09)$ & 5 & $19.38(2.39-36.37)$ & 1 & $4.20(-4.03-12.44)$ & 0 & 0 \\
\hline Hyperextension & 1 & $2.73(-2.62-8.09)$ & 0 & 0 & 0 & 0 & 0 & 0 \\
\hline Epistaxis & 6 & $16.39(3.28-29.51)$ & 0 & 0 & 2 & $8.40(-3.24-20.05)$ & 0 & 0 \\
\hline Cramps & 3 & $8.20(-1.08-17.47)$ & 1 & $3.88(-3.72-11.47)$ & 0 & 0 & 0 & 0 \\
\hline Incision & 3 & $8.20(-1.08-17.47)$ & 3 & $11.63(-1.53-24.79)$ & 0 & 0 & 0 & 0 \\
\hline Dizziness & 2 & $5.46(-2.11-13.04)$ & 0 & 0 & 0 & 0 & 0 & 0 \\
\hline Nerve injury & 1 & $2.73(-2.62-8.09)$ & 0 & 0 & 0 & 0 & 0 & 0 \\
\hline Tendinitis & 2 & $5.46(-2.11-13.04)$ & 0 & 0 & 0 & 0 & 0 & 0 \\
\hline Impingement & 1 & $2.73(-2.62-8.09)$ & 1 & $3.88(-3.72-11.47)$ & 0 & 0 & 0 & 0 \\
\hline Others & 0 & 0 & 2 & $7.75(-2.99-18.50)$ & 1 & $4.20(-4.03-12.44)$ & 0 & 0 \\
\hline
\end{tabular}

$\mathrm{CI}$ - confidence interval; A-E - athlete exposure.

were not clear. However, women almost showed a higher risk than girls $(\mathrm{OR}=6.30,95 \% \mathrm{CI}: 1.26-31.66)$.

Men sustained more injuries to their upper body than to their lower body and they were also at a higher risk of sustaining an injury to that body region compared to women $(\mathrm{OR}=4.17,95 \% \mathrm{CI}: 1.57-11.08)$. Although, the upper body injuries in women were also higher than their lower body injuries, the CIs were overlapping (Table 2). Boys also sustained more injuries to their upper limbs than to lower body region as well as compared to their counterparts $(\mathrm{OR}=1.71,95 \% \mathrm{CI}: 0.52-5.62)$. No such relationship was apparent in girls. The girls have the same number of injuries for both body regions..

Abrasions were common in all age divisions and were diagnosed more often in men, women and girls (Table 3). Contusions were also present in women, boys and girls, but were diagnosed most often in boys. Majority of the athletes trained three times a week (49\%), followed by those training four times or more $(30 \%)$, and those who practiced at the most twice a week $(21 \%)$. More than half of those who got injured had training sessions lasting at least two hours (57\%) while the rest trained under 2 hours. A total of $74 \%$ of the athletes were engaged in different types of training other than judo. The training variables predicted $3 \%(\mathrm{SEE}=0.439)$ of the variance in injury occurrence, which was not significant $(p=0.061)$. Frequency barely contributes to the chance of sustaining an injury $(\mathrm{p}=0.045)$, and neither does duration $(\mathrm{p}=0.345)$.

Supplemental training was not related to the occurrence of injuries $(\mathrm{p}=0.712)$. The overall percentage of correct predictions was 73.40 (95\% CI: 66.78-79.18).

\section{Discussion}

Only a few other studies have been conducted on judo injuries using incidence rates per A-E. The injury rates in this study population were higher than the injury rates in British athletes practicing judo, which were 39.76/1,000 A-E (95\% CI: 29.15-50.37) and 52.08/1,000 A-E (95\% CI: 36.86-67.30) in junior men and women, respectively [11]. The number of injuries in boys, on the other hand, was comparable to the results of a study in the UK [30] (79.70/1,000 A-E (95\% CI: 46.40-113.52)) although this was not the case for the injury rates in girls $(98.60 / 1,000$ A-E (95\% CI: 46.95-150.24)).

Compared to other martial arts, statistically significant differences in injury rates in girls were found between Filipino judo athletes and German karatekas [23] (190.48/1,000 A-E (95\% CI: 114.27-266.69)) as well as Canadian taekwondo athletes [31] (134.62/1,000 A-E (95\%: 64.10-205.14)), with Filipino girls showing lower rates. Junior Filipino men and women sustained significantly more injuries than their Greek taekwondo counterparts [6]; injury rates were 108.97/1,000 A-E and 54.70/1,000 A-E in the Filipino and Greek athletes, respectively. One reason for this may be related to the sample size of the Filipino group. It has been reported that with smaller sample sizes, injury rates tend to be larger [6] and confidence intervals wider [31]. It may also be possible that Filipino boy judoka were taught techniques that are considered to be more advanced relative to their skill level. In some cases, it has been suggested that coaches are more focused on 
winning than on the participation and enjoyment of young judo athletes [42].

The injury rates of the younger judokas in the current study, however, were lower than those found in a more recent study [31] of Canadian boys (134.62/1,000 A-E, 95\% CI: 64.10-205.14) and girls (333.33/1,000 A-E, 95\% CI: 170.00-496.66) who practiced taekwondo. Dutch boy and girl karatekas also incurred more injuries (99.74/1,000 A-E (95\% CI: 77.32-122.16) and 115.11/1,000 A-E (95\% CI: 75.23-154.99), respectively [28]. Although the estimated percentages of injuries in the other studies were higher, the CIs generally overlap with the CIs of this study and do not clearly demonstrate significant differences, except between Filipino and Canadian girls. A look at the exposure times in all of the preceding studies reveals that there is no linear relationship between injury rate and the amount of time spent in the activity.

A comparison by sex reveals that junior women have a higher injury incidence rate than their male counterparts though this is not significant. Similar findings were reported by Pieter and colleagues [32] in elite adult judo athletes. In taekwondo, female British competitors also exhibited similar characteristics [29], and the same pattern was observed in Dutch girl karatekas [28] and their Croatian counterparts [20]. It has been suggested that female athletes are more inclined to report an injury [4], although this has not been consistently confirmed via statistical analyses. It may be that the skills of the girls in protecting themselves from injuries as a result of falling are not on par with those of the boys. The girls in these studies may also not be as physically conditioned as the boys. More research is needed on the age group ranging from 8 to 19 years. On the other hand, the finding that boys reported more injuries than girls may suggest a higher level of competition among the boys, although other studies found no relationship between experience and injury rates [8].

It is worth mentioning that the lack of significant differences in the injury rates between boys and junior men is cause for concern considering the fact that children might have to suffer the consequences of these injuries later in life. Helms [9] expressed concern about mismatches in terms of age based on date of birth as the usual source of inequality in competition leading to an increased risk of injury. Another concern is the high number of injuries among young competitors in this study compared with injuries in older and more experienced elite athletes: men exhibited a total injury rate of $48.54 / 1,000$ A-E $(95 \%$ CI: 18.46-78.63) and women exhibited a total injury rate of only 34.25/1,000 A-E (95\% CI: 4.23-64.27) [12].

The data show that in the junior competitors, the upper body is the most commonly injured body region, however, the head and neck region was found to have an increased susceptibility to injury as well . The head has been reported to be the most injured site in other martial arts. In a study of young karate athletes covering two periods (1997 and 2002), Macan and colleagues [21] found that both male and female athletes sustained more injuries to the head than to any other parts of the body.

A similar concern regarding head injuries was demonstrated in an 8-year documentation of head and neck injuries reported in Japan from 2003-2010, where 90\% of head injuries were sustained by judo athletes 20 years old and younger [14]. From the 72 reported injuries, 15 athletes died of head injuries, and 7 experienced complete paralysis due to injuries to the neck. The most common mechanism of injury to the head was a lack of proper falling technique (ukemi), especially among beginners. On the other hand, neck injuries occurred mostly during offensive manoeuvers.

Higher injury rates to the upper extremities have been reported for British athletes. The fingers and shoulders were common sites of injury [8], while the elbow was the most susceptible to harm in junior women [11]. The joint-locking style common in grappling situations is a contributing factor to these injuries [12]. The elbow has also been reported as being susceptible to harm for several reasons, such as improper falling techniques [22]. It is also common for referees to not quickly see the submission of some judoka during an arm lock, leading to serious ligament injury [12]. On the other hand, among elite male Asian athletes, the wrist was found to be the body part that was most injured [32]. Injury to the wrist and fingers is to be expected as the sport of judo generally starts with grip fighting, with each judoka trying to gain control of the other. Consistent with the findings reported here, the upper extremities, specifically the hands and forearm, were injured most often.

In contrast, among adult judoka, the knee was found to be the most susceptible to harm. In studies done by Souza and colleagues [37] and Barsottini and colleagues [5], knee injuries made up $26.36 \%$ and $23 \%$ of total injuries, respectively, in Brazilian competitors. The nature of the movements during the execution of techniques most likely led to both ligamentous and meniscal stress [37].

An abrasion was the most common type of injury in all age divisions in this study except for the boys. This is consistent with findings reported by Pieter and colleagues [32] in elite judoka. Mat injuries are consistent with the nature of the sport, with contestants incurring burns or bruises upon impact with the surface [8] or during grappling.

Contusions were the second most frequent injuries for all age groups except in the junior men, with epistaxis coming in second. This is consistent with what has been reported for British elite female athletes [12]. In comparison with other martial arts, contusions are the most common type of injury in karate [2] and taekwondo [27]. Muscle strains are also common, not only in judo but also 
in kickboxing [34]. Muscle strains might be incurred due to repeated body collisions during attack and defence manoeuvers. In addition, the high muscle contractions forces involved in resisting throwing and even grappling attempts might result in such injuries. It should be noted, however, that injuries may not always be reported, including serious ones, such as concussions and fractures [32].

With respect to training variables, training frequencies of $\leq 2,3$, and $\geq 4$ sessions per week were not significant predictors of injury in this study, nor were training durations of $\leq 2$ and $>2$ hours. Similarly, no link between the occurrence of serious sports injuries and the number and duration of daily and weekly training sessions was found in a study done on 520 athletes from different sporting events, including judo, from Serbia and Montenegro [3]. Most of the athletes surveyed trained once a day (men $70.2 \%$; women $-75.8 \%$ ), 2 hours a day (men $-35.3 \%$; women $-37.7 \%$ ), and 5 times a week (men $-24.6 \%$; women $-32.3 \%$ ). Adult elite athletes trained twice as long as their younger counterparts, but surprisingly, injuries in these older athletes were not found to occur twice as often. This finding implies that there is no simple relationship between the occurrence of injuries and training variables such as duration and frequency. Other equally important factors contributing to injuries should be considered, including psychological characteristics, such as anxiety and mood, which have been found to be related to performance in martial arts in Caucasian [38] and Asian [40] athletes.

However, Zetaruk and colleagues [42] considered the frequency of training in their comparison of five martial arts and found that a training time of more than three hours was a significant predictor of injury (OR 1.85; 95\% CI: 1.13-3.05), together with other variables such as age $(<18$ vs. $\geq 18)$, sex, experience ( $<3$ years in the sport vs. $\geq 3$ years), rank (black belts vs. lower belts), and martial art style. It seems that longer training durations expose athletes to an increased risk of injury.

Supplemental training was not found to be related to the occurrence of injuries in this study. It was not established whether those who engaged in any exercise outside judo practice were more injury-resistant than those who trained only in judo. The importance of both the technical aspects of judo and the development of physiological parameters may enhance performance as well as prevent injury [1]. It should also be noted that although a few of the participants actually got injured in competition, injuries incurring during training are far harder to avoid [24].

Suggestions for preventive measures include the installation of an under-mat for shock absorption [12] and more focus on falling exercises, especially for beginners [14], as well as the modification and strict implementation of competition rules [26]. Green and colleagues [8] also advised against rapid weight loss, as doing so increases the risk of injury. Efforts to educate athletes and coaches, as well as referees and tournament officials, regarding injuries and injury prevention should also be a priority [33].

In the present investigation, we were not able to collect data regarding injury situation and mechanism which may be mandatory for a pure epidemiological study. This may have allowed us to more or less describe possible causes for injury. Also, we only surveyed one competition, which gave us a small sample size. Larger sample sizes are needed to further investigate the role of training variables in predicting the occurrence of injuries as well as supplemental training. Also, the same variables should not be restricted to two or three options to gain a more accurate scenario of the training practices of athletes. One option is to ask for the exact frequency instead of grouping them. This will also make it easier to analyze the data. Furthermore, a time-loss definition of injury was not used in this study, which accounted for more minor injuries to be reported.

\section{Conclusions}

The current study presents an initial survey of competition injuries in young judo athletes in the Philippines and the possible association between competition injuries and training variables. Based on the results of this study, most injuries incurred in competition were less serious. The risks of injuries in all divisions were the same. If considered, the occurrence of time-loss injuries, however, may be different. The frequency and duration of training were not found to influence the likelihood of injury, and supplemental training was not found to lower the risk of getting injured. More epidemiological studies on injuries in young judo athletes should be carried out to establish a more conclusive profile for this population. It should be noted, however, that total injury rates are just the tip of the iceberg. Further investigations should also consider including injury situations and mechanisms so that preventative measures may be suggested to help reduce the occurrence of injuries. The injury rates reported here are comparable to the results of other studies done in similar populations and in other types of martial arts. A follow-up study sampling a larger number of athletes at several competitions is recommended to provide a more complete picture of the epidemiology of judo injuries in the Philippines.

\section{References}

1. Amtmann J., A. Cotton (2005) Strength and conditioning for judo. Natl. Strength Cond. Assoc., 27: 26-31.

2. Arriaza R., M. Leyes (2005) Injury profile in competitive karate: prospective analysis of three consecutive World Karate Championships. Knee Surg. Sports Traumatol. 
Arthrosc., 13: 603-607. http://dx.doi.org/10.1007/s00167009-0856-3

3. Bacanac L.R., M. Radovic, A. Veskovic (2007) Frequency of sports injuries depending on gender, age, sports experience, nature of sports and training process. Serbian J. Sports Sci., 1: 122-128.

4. Barrault D., B. Achou, R. Sorel (1983) Accidents et incidents survenus au cours des compétitions de judo. Symb., 15: 144-152.

5. Barsottinni D., A.E. Guimaraes, P.R. de Morais (2006) Relationship between techniques and injuries among judo practitioners. Rev. Bras. Med. Esporte, 12: 48e-51e.

6. Beis K., P. Tsaklis, W. Pieter, G. Abatzides (2001) Taekwondo competition injuries in Greek young and adult athletes. Eur. J. Sports Trauma. Relat. Res., 23: 130-136. (Abstract).

7. Caine D.J., C.G. Caine, K.J. Lindner (1996) The epidemiologic approach to sports injuries. In: D.J. Caine, C.G. Caine and K.J. Lindner (eds.) Epidemiology of Sports Injuries. Human Kinetics, Champaign, Illinois. p. 4.

8. Green C.M., M.J. Petrou, M.L.S. Fogarty-Hover, C.G. Rolf (2007) Injuries among judokas during competition. Scand J Med Sci Sports, 17: 205 - 210. http:// dx.doi.org/10.1111/j.1600-0838.2006.00552.x

9. Helms P.J. (1997) Sports injuries in children: Should we be concerned? Arch. Dis. Child., 77: 161-163. http:// dx.doi.org/10.1136/adc.77.2.161

10. International Judo Federation [homepage on the internet]. Federations [accessed 2016 July 19]. AJU, PJC, JUA, EJU, OJU; [5 screens]. Retrieved from: http://www.ijf.org/

11. James G., W. Pieter (1999) Competition injuries in young judo athletes. Paper presented at: $1^{\text {st }}$ International Judo Federation Judo Conference, Oct. 4-5, Birmingham, U.K.

12 James G., W. Pieter (2003) Injury rates in adult elite judoka. Biol Sport, 20: 25-32.

13. JUDO: participation during the history of the Olympic Games. Olympic Studies Centre: Research and Reference Service 2011; 1-4 [accessed 2016 May 12]. Retrieved from: http://www.olympic.org/Assets/OSC $\% 20$ Section/pdf/QR_sports_summer/Sports_Olympiques_ judo_eng.pdf

14. Kamitani T., Y. Nimura, S. Nagahiro, S. Miyazaki, T. Tomatsu (2013) Catastrophic head and neck injuries in judo players in Japan from 2003-2010. Am. J. Sports Med., 20: 1-7. http://dx.doi.org/10.1177/0363546513490662

15. Kano J. (1986) Kodokan Judo. Kodansha International, Tokyo, Japan. pp. 20-25, 42-44.

16. Koiwa E.K. (1981) Fatalities associated with judo. Phys. Sportsmed., 9: 61-66.

17. Koshida S., T. Deguchi, K. Miyashita, K. Iwai, Y. Urabe (2008) The common mechanism of anterior cruciate ligament injuries in judo: a retrospective analysis. Br. J. Sports Med., 1-17. http://dx.doi.org/10.1136/bjsm.2008.051425
18. Kujala U.M., S. Taimela, I. Antti-Poika, S. Oraya, R. Tuominen, P. Myllynen (1995) Acute injuries in soccer, ice hockey, volleyball, basketball, judo, and karate: analysis of national registry data. BMJ., 311: 1465-1468.

19. Kurosawa H.N. (1996) Complete avulsion of the hamstring tendons from the ischial tuberosity: A report of two cases sustained in judo. Br. J. Sports Med., 30: 72-74.

20. Macan J., D. Bundalo, G. Romić (2001) The prevalence and distribution of injuries in karate (kumite). Kines., 33: 137-145

21. Macan J., D. Bundalo-Vrbanac, G. Romić (2006) Effects of the new karate rules on the incidence and distribution of injuries. Br. J. Sports Med., 40: 326-330. http://dx.doi. org/10.1136/bjsm.2005.022459

22. McLatchie G.M. (1979) Combined force injury of the elbow joint - the mechanism clarified. Br. J. Sports Med., 13: 176-179.

23. Müller-Rath R., O. Miltner, M. Mamarvar, T. Mumme (2005) Das verletzungsrisiko im jugend - un juniorenwettkampfkarate. Risk of injury in junior competitive karate. Sportverl Sportschad, 19: 191-194.

24. Oliveira T.S., J.S. Pereira (2008) Frequency of articulation injuries in judo. Fit. Perf. J., 7: 375-379. http:// dx.doi.org/10.3900/fpj.7.6.375.e

25. Olympic.org: Official website of the Olympic Movement [homepage on the internet]. The International Olympic Committee [accessed 2016 July 19]. National Olympic Committees; [1 screen]. Retrieved from: http://www.olympic.org/ioc-governance-national-olympic-committees

26. Pieter W. (2005) Martial arts injuries. In: D.J. Caine, N. Maffulli (eds.) Epidemiology of Pediatric Sports Injuries. Inidividual Sport. Med Sport Sci. Karger, Basel, pp. 59-73.

27. Pieter W. (2009) Taekwondo. In: D.J. Caine, P. Harmer, M. Schiff (eds) Epidemiology of Injury in Olympic Sports. International Olympic Committee Encyclopaedia of Sports Medicine. Wiley-Blackwell, Oxofrd. pp. 249-259.

28. Pieter W. (2010) Competition injury rates in young karate athletes. Sci., Sports, 25: 32-38. http://dx.doi. org/10.1016/j.scispo.2009.07.001

29. Pieter W., L.T. Bercades, J. Heijmans (1998) Injuries in young and adult taekwondo athletes. Kines., 30: 22-30. http://dx.doi.org/10.1589/jpts.28.231

30. Pieter W., C. De Crée (1997) Competition injuries in young and adult judo athletes. Paper presented at: $2^{\text {nd }}$ Annual Congress of the European College of Sports Science, Aug 20-23; Copenhagen, Denmark.

31. Pieter W., M. Kazemi (2007) Competition injuries in young Canadian taekwondo athletes. In: Song JK, Yoo $\mathrm{SH}$, editors. $1^{\text {st }}$ International Symposium for Taekwondo Studies. Beijing: Capital Institute of Physical Education. pp. 197-206. 
32. Pieter W., C. Talbot, V. Pinlac, L. Bercades (2001) Injuries at the Konika Asian Judo Championships. Acta Kines. Univ. Tart., 6: 102-111.

33. Pocecco E., G. Ruedl, N. Stankovic, S. Sterkowicz, F.B. Del Vecchio, C. Gutiérrez-García et al. (2013) Injuries in judo: A systematic literature review including suggestions for prevention. Br. J. Sports Med., 47: 1139-1143. http://dx.doi.org/10.1136/bjsports-2013-092886

34. Romaine L.J., S.E. Davis, K. Casebolt, K.A. Harrison (2003) Incidence of injury in kickboxing participation. J. Strength Cond. Res., 3: 580-586.

35. Russo M., N. Maffulli (1991) Dorsal dislocation of the distal end of the ulna in a judo player. Acta Orthop. Belg., 57: 442-446.

36. Sheppard N.P., R.B. Westrick, B.D. Owens, M.R. Johnson (2013) Bony avulsion injury of the pectoralis major in a 19-year old male judo athlete: A case report. Int. J. Sports Phys. Ther, 8: 862-870.

37. Souza M., H. Monteiro, F. Del Vecchio, A. Goncalves (2006) Referring to judo's sports injuries in Sao Paolo State Championship. Sci. Sports, 21: 280-284. http:// dx.doi.org/10.1016/j.scispo.2006.06.002

38. Terry P., A. Slade (1995) Discriminant effectiveness of psychological state measures in predicting performance outcome in karate competition. Percept Motor Skills, 81: 275-286. http://dx.doi.org/10.2466/pms.1995.81.1.275

39. Weightman D., R.C. Browne (1975) Injuries in eleven selected sports. Br. J. Sports Med., 9: 136-141. http:// dx.doi.org/10.1136/bjsm.9.3.136

40. Wong R.S.K., J.S. Thung, W. Pieter (2006) Mood and performance in young Malaysian karateka, Journal of
Sport Science and Medicine, Combat Sports Special Issue: $54-59.41$.

41. Yard E.E., C.L. Knox, G.H. Smith, R.D. Comstock (2007) Pediatric martial arts injuries presenting to emergency department, United States 1990-2003. J. Sci. Med. Sport, 10: 219-226. http://dx.doi.org/10.1016/j.jsams.2006.06.016

42. Zetaruk M.N., M.A. Violan, D. Zurakowski, L.J. Micheli (2005) Injuries in martial arts: a comparison of five styles. Br. J. Sports Med., 39: 29-33. http://dx.doi.org/10.1136/ bjsm.2003.010322

43. Zemper E.D, R.W. Dick (2007) Epidemiology of Athletic Injuries. In: D. McKeag and J. Moeller (eds.). Primary Care Sports Medicine, $2^{\text {nd }}$ ed. Lippincott William and Wilkins, Philadelphia, PA, pp. 11-28.

\section{Received 21.09.2016 \\ Accepted 06.12.2016}

(C) University of Physical Education, Warsaw, Poland

\section{Acknowledgments}

The authors extend their appreciation to the student assistants who helped collect the data, the tournament physician and other medical personnel for their technical assistance, and to Dr. Willy Pieter for help in the statistics. This study was funded by the University of the Philippines under the Office of the Vice Chancellor for Academic Affairs. 